\title{
CAFFEINE BEVERAGE CONSUMPTION BEHAVIOR AMONG WORKING AGE GROUP IN KHON KAEN PROVINCE, THAILAND
}

\author{
Phuwasin Buakate, Ratthaphol Kraiklanng, \\ Wongsa Laohasiriwong, Thanida Patisena \\ Faculty of Public Health, KhonKaen University, Thailand \\ Board Committee of Research and Training Center for Enhancing \\ Quality of Life of Working Age People, KhonKaen University, Thailand
}

\begin{abstract}
BACKGROUND: A nonlinear association between coffee consumption and CVD risk was observed in meta-analysis. Moderate coffee consumption was inversely significantly associated with CVD risk, with the lowest CVD risk at 3 to 5 cups per day. Heavy coffee consumption was not associated with elevated CVD risk.There has been an increasing trend of caffeine beverage consumption in Thailand. However, little was known about the consumer behavior on caffeine beverage among the working age group in Thailand. This study aimed to describe caffeine beverage consumption behavior among working age group in Khon Kaen province, Thailand.

SUBJECT AND METHODS: This descriptive cross sectional study was conducted in Khon Kaen province, Thailand. A sample of 412 coffee drinkers aged 18-59 years old was selected by multistage random sampling from the working age population. A structured questionnaire was developed and tested for content validity by 3 experts. Cronbach alpha coefficient was 0.89 .
\end{abstract}

RESULTS: The majority of 412 coffee drinkers were female (59.95\%), with the average age of $36.61 \pm 13.20$ years old, married $(64.32 \%), 36.41 \%$ finished senior high school and $25 \%$ working in agricultural sector. Their median monthly income ( $\min , \max$ ) was 9,000 (0, 70000) baht. Over the past month, 88.83\% reported consuming caffeine beverage (95\%CI: $85.78 \%$ to $91.88 \%$ ). Caffeine beverage most commonly consumed was cola (38.10\%). The median amount of coffee $(\mathrm{ml})$ per time (min, max) was 250 $(180,1500) \mathrm{ml}$. The median monthly expense (min, max) for caffeine beverage was $600(90,3000)$ baht. Most coffee drinkers got coffee beverage information from television (61.75\%). However, only $27.67 \%$ had high level of knowledge on caffeine beverage. 75.00\% thought it was easy to access, $65.29 \%$ liked the taste, $53.64 \%$ believed in the caffeine beverage advertisement. $58.28 \%$ perceived price was appropriate, and $41.26 \%$ thought caffeine beverage was good for health.

CONCLUSION: Almost all of the working age group in Khon Kaen province, Thailand, drink caffeine beverage. Information, environment and marketing may have influence on their consumption behavior.

Keywords: caffeine beverage, behavior, working age group 